\title{
Memorial for Michael Davidson, MD
}

R. Morton Bolman III, MD, on behalf of the Division of Cardiac Surgery, Brigham and Women's Hospital

On January 20, 2015, the world of the Brigham and Women's Hospital was sent careening off its axis. The life and career of Brigham cardiac surgeon, Michael J. Davidson, MD, so full of early promise and accomplishment, and of future potential without limit, was abruptly and prematurely brought to an end, at the age of only 44 years, in an act of inexplicable violence and stunning finality. Michael was a preternaturally gifted individual whose parents-father, Bob, a cardiologist, and mother, Susan, a psychologist - and sister, Hilary, a human rights attorney, were ardent and devoted supporters throughout his life.

Michael was an outstanding student throughout his academic career-undergrad at Princeton, medical school at Yale, surgical training at Duke, and subsequently at Brigham and Women's Hospital. At Princeton, as noted in an insightful memorial in The Daily Princetonian, Michael majored in philosophy while completing studies for the pre-

From the Division of Cardiac Surgery, Brigham and Women's Hospital, Boston, Mass.

Disclosures: Author has nothing to disclose with regard to commercial support.

This article is copublished in The Annals of Thoracic Surgery.

Address for reprints: R. Morton Bolman III, MD, Division of Cardiac Surgery,

Brigham and Women's Hospital, 75 Francis Street, Boston, MA 02115 (E-mail:

rbolman@partners.org).

J Thorac Cardiovasc Surg 2015;149:1240-1

$0022-5223 / \$ 36.00$

Copyright (C) 2015 by The American Association for Thoracic Surgery and The Society of Thoracic Surgeons

http://dx.doi.org/10.1016/j.jtcvs.2015.02.056

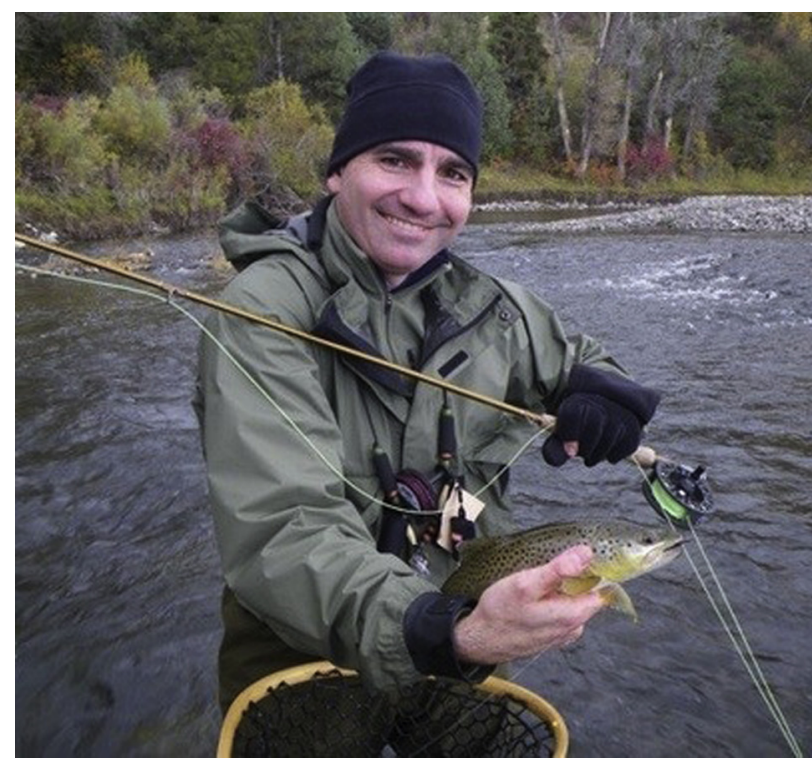

FIGURE 1. Michael showing prowess on the stream.

medical curriculum. He always manifested a concern for those less fortunate than him. At Princeton, his thesis was entitled "Universalizing Access to Health Care: Social Justice and the Duty of Beneficence." He argued that the United States has a duty to provide a basic level of access to health care to all of its citizens. His thesis advisor, Professor Amy Gutmann, who is now President of the University

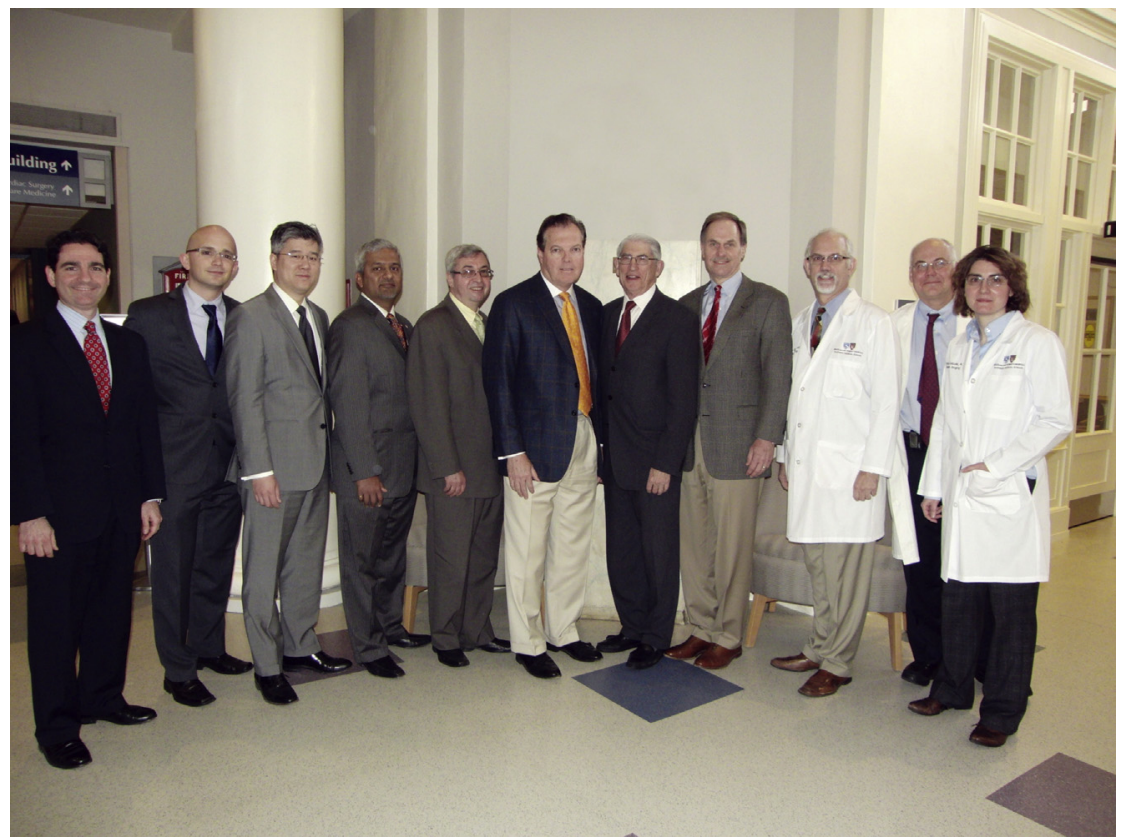

FIGURE 2. Michael with his colleagues in the Division of Cardiac Surgery, Brigham and Women's Hospital. 
of Pennsylvania, said that Michael Davidson "was a wonderful student and wise at a remarkably young age. Above all, he was a caring person who dedicated his tragically short life to doing everything in his power to help others in need, which was precisely what he provided with the most expert hands and caring heart."

Michael was truly a visionary in cardiac surgery and heart care in general. Perhaps because of his wide-ranging interests-music, photography, fly fishing, aviation, fencing, running - each of which he engaged with an unabashed passion (Figure 1), Mike looked at the world as a place just waiting for someone with bold dreams and the courage to follow them. He determined that the cardiac surgeon and cardiologist of the future needed to have far more in common with each other in terms of skills and approaches to treating heart disease. Following the maxim of another pioneering cardiac surgeon, Norman Shumway, that "the best way to predict the future is to invent it yourself," Mike engineered a new training pathway for cardiac surgeons by being among the very first of that specialty to become fully trained in the catheter skills necessary to perform interventions for structural heart disease. He accomplished this by completing an extra "hybrid" training year-50\% in the catheterization lab, $50 \%$ in the operating room-following completion of his thoracic surgery residency.

After successful completion of this new training paradigm, Mike joined the faculty in cardiac surgery at the Brigham and Women's Hospital in 2006 (Figure 2). He assumed the lead role in this new field at the interface of cardiology and cardiac surgery, and, with his colleagues in interventional cardiology, created a "heart team" to address the management of structural heart disease. This "heart team" concept is now being copied in other areas of cardiology and cardiac surgery, but it had its origin in the field of structural heart disease. Michael Davidson was a true pioneer in this burgeoning field. $\mathrm{He}$ envisioned the future of heart care, pioneered the pathway to prepare himself to be a leader, and lived this brave new

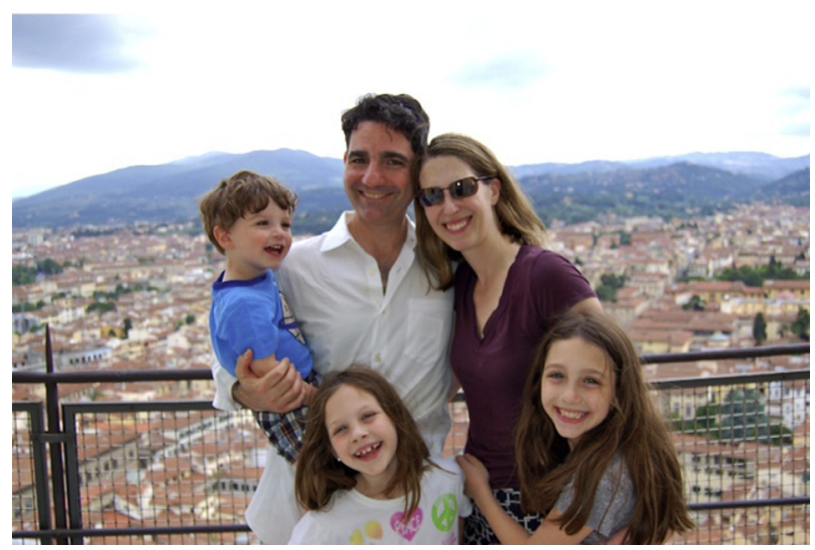

FIGURE 3. Michael with his lovely family on a recent trip to Italy.

vision of integrated cardiac care, albeit for far too short a time. Indeed, Michael was the ideal individual to represent cardiac surgery in this evolution. He was a total team player, and his only goal was giving each patient the best possible treatment. Michael embodied the "heart team" in the way he practiced medicine and in the way in which he conducted himself in all his interactions with colleagues, patients, families, and everyone with whom he came in contact.

Without doubt, of all the blessings and achievements in his life, Mike was proudest of his lovely and growing familywife, Terri, a practicing plastic surgeon and Mike's loving partner on this journey, and their 3 children: Kate, age 9 , Liv, age 7 , and Graham, age $2 \frac{1}{2}$ (Figure 3). Their fourth child, a daughter, is due in April.

Those of us remaining behind in the wake of this senseless tragedy can never understand why it happened. We can only take consolation in our good fortune to have had the opportunity to share in the life of the unique human being who was Michael Davidson, a true Renaissance man-loving husband and father, son and brother, caring physician, innovative surgeon, and loyal friend. 